\title{
Investigação Sociológica sobre o Futebol de Várzea na Comunidade São Gonçalo Beira Rio em Cuiabá/MT*
}

\author{
Francisco Xavier Freire Rodrigues \\ Universidade Federal de Mato Grosso - fxsociologo@yahoo.com.br
}

Allan Kardec Pinto Acosta Benitez

Universidade Federal de Mato Grosso - ver.allankardec@gmail.com

\begin{abstract}
Sumário
O texto apresenta resultados de uma pesquisa sobre o futebol de várzea em Cuiabá/MT. O objetivo da investigação é estudar o futebol de várzea como mediador da cultura e das relações sociais na Comunidade São Gonçalo Beira Rio, em Cuiabá/MT. Pretende-se também: a) apresentar e analisar as estratégias de fundação dos times de futebol amador na Comunidade São Gonçalo Beira Rio; b) descrever e entender os aspectos oganizacionais do futebol de várzea na comunidade investigada; c) analisar as formas/manifestações de relações, conflitos, embates e contradições entre os times de futebol daquela comunidade. Que papel teria o futebol de várzea na mediação das diferenças locais, que maneiras de fazer sua prática interatuam e modificam o espaço

e as relações? A História de Vida foi o método utilizado, tendo como técnica de coleta de dados entrevistas semiestruturadas, registradas durante a pesquisa de campo. O futebol de várzea desempenha papel de mediação cultural na comunidade pesquisada, sendo veículo de interação social, produtor de aproximações e conflitos sociais, culturais e políticos. Aprofundamos mais ainda, ao deparar-nos com intensa participação da comunidade ao redor do campo de futebol de várzea, observando por exemplo - que a vida na e da comunidade São Gonçalo Beira Rio, como pudemos constatar, ganhava outro ritmo nos dias de jogos, e o cotidiano da rotina caseira quebrava-se e transformava-se em outras rotinas que o campo de futebol exigia dos moradores.
\end{abstract}

Palavras-chave: Futebol de várzea, Cuiabá/MT, manifestação cultural, lazer.

\section{Sociological Research on Várzea Football in the Community São Gonçalo Beira Rio in Cuiabá/MT}

\begin{abstract}
The text presents results of a survey on the floodplain football in Cuiabá / MT. The goal of the research is to study the floodplain football as cultural mediator and social relations

in the Community São Gonçalo Beira Rio in Cuiabá/MT. It is also intended: a) to present and analyze the strategies of founding amateur football teams in the São Gonçalo Beira Rio

\footnotetext{
* Este artigo constitui uma versão revista de uma comunicação apresentada no $18^{\circ}$ Congresso Brasileiro de
} Sociologia que decorreu em Brasília, entre 26 e 29 de julho de 2017.
\end{abstract}


Community; b) describe and understand the organizational aspects of floodplain football in the researched community; c) analyze the forms/manifestations of relations, conflicts, clashes and contradictions between the football teams of that community. What role would varzean football play in mediating local differences, what ways of doing their practice interact and modify space and relationships? The Life History was the method used, having as data collection technique semi-structured interviews, recorded during field research. The várzea football plays cultural media- tion role in the research community, being a vehicle for social interaction, producer of approaches and social conflicts, cultural and political. Deepened further when confronted us with intense community participation around the várzea football field, watching - for example - that life in and São Gonçalo Beira Rio community, as we have seen, earned another rhythm on match days, and the routine of the home routine was broken and became other routines that the football field demanded from the residents.

Keywords: Várzea football; Cuiabá/MT, cultural manifestation, recreation.

\section{INTRODUÇÃO}

Analisar o futebol de várzea como mediador cultural possibilita adentrar no cotidiano do lazer que é praticado e mantido nos mais inusitados rincões deste Brasil, seja na cidade, seja no campo. Esse cotidiano se revela múltiplo, repleto de (re)invenções e improvisações que o dinamizam e o mantêm no imaginário popular, nos relatos de vida, nos fins de semana sociabilizados ou mediados pelas partidas de futebol que contam, ademais de empates, vitórias e derrotas, maneiras de fazer o lazer de cada lugar.

Analisar e compreender esse papel mediador, função silenciosa tanto quanto ruidosa dada ao futebol de várzea, leva-nos a perceber a multiplicidade de campos/esferas que se imbricam nesse jogo de relações sociais, culturais, comunicativas, antropológicas, históricas; enfim, são tantas as facetas quanto as possibilidades analíticas e explicativas que o futebol de várzea apresenta para entendermos as relações sociais no Brasil.

O objeto de estudo deste artigo foi o futebol de várzea na Comunidade São Gonçalo Beira Rio, em Cuiabá/MT, Brasil, tendo como preocupação desvendar aspectos relacionados à cultura e às relações sociais naquela comunidade. O problema de pes- 
quisa aqui apresentado foi: Que papel teria o futebol de várzea na mediação das diferenças locais, que maneiras de fazer sua prática interatuam e modificam o espaço e as relações? Essa questão foi respondida através da articulação entre conceitos e dados empíricos coletados na pesquisa de campo por meio de entrevistas e observações sistemáticas. As narrativas contam sobre as maneiras de fazer, viver e praticar o futebol, reveladoras de percursos e trajetórias de dois times locais de futebol de várzea: São Gonçalo Beira Rio Futebol Clube e Milionários Futebol Clube, ambos criados no seio da Comunidade São Gonçalo Beira Rio, em Cuiabá/MT.

Os objetivos da investigação que gerou este texto ultrapassam as fronteiras de mero registro histórico daquelas práticas e recaem principalmente sobre a importância da temática proposta, uma vez que esta nos permite evidenciar as histórias de vida de atores sociais que construíram, através do futebol de várzea, uma trajetória do lazer que ocupou aquele espaço comunitário, bairro isolado do centro urbano de Cuiabá/MT, e mediou conflitos locais de resistências e fronteiras sociais. Explicitando melhor, os objetivos da investigação foram: estudar o futebol de várzea como mediador da cultura e das relações sociais na Comunidade São Gonçalo Beira Rio, em Cuiabá/MT, sendo este o objetivo geral. Os específicos foram: a) apresentar e analisar as estratégias de fundação dos times de futebol amador na Comunidade São Gonçalo Beira Rio; b) descrever e entender os aspectos oganizacionais do futebol de várzea na comunidade investigada; c) analisar as formas/manifestações de relações, conflitos, embates e contradições entre os times de futebol daquela comunidade.

A hipótese defendida é de que o futebol de várzea desempenha importante papel na mediação cultural e nos conflitos sociais na Comunidade São Gonçalo Beira Rio (SGBR) e de que há inúmeras maneiras de fazer o futebol de várzea em SGBR, onde "as operações multiformes e fragmentárias, relativas a ocasiões e detalhes" (De Certeau, 1998, p. 42) supostamente apresentam uma lógica na sua prática. O futebol é um agente produtor de rivalidades, oposições, sociabilidades e de identidades sociais (Giulianotti, 2010).

A História de Vida foi o método utilizado, tendo como técnica de coleta de dados entrevistas semiestruturadas, registradas durante a pesquisa de campo. Utilizou-se também da observação sistemática.

O texto foi estruturado nas seguintes partes: Introdução, Percurso Metodológico, Aporte Teórico-Conceitual, O Futebol de Várzea em Cuiabá/MT, Considerações Finais e Referências Bibliográficas. 


\section{PERCURSO METODOLÓGICO}

Considerando-se que o objeto da investigação deste texto foi o futebol de várzea como mediador da realidade sociocultural vivida na Comunidade São Gonçalo Beira Rio, ou dito no modo de Michel de Certeau, suas maneiras de fazer, há que se pontuar o destaque dado aqui ao conhecimento popular, que segundo Babini (1957, p. 21, citado por Lakatos \& Marconi, 2000, p. 17), “é o saber que preenche nossa vida diária e que se possui sem o haver procurado ou estudado, sem a aplicação de um método e sem se haver refletido sobre algo".

Conhecimento popular é aquele que traz características peculiares - de acordo com Ander-Egg (1978, pp. 13-4, citado por Lakatos \& Marconi, 2000, p.21), como ser: superficial, isto é, conforma-se com a aparência, com aquilo que se pode comprovar simplesmente estando junto das coisas; sensitivo, ou seja, referente a vivências, estados de ânimo e emoções da vida diária; subjetivo, ou próprio do sujeito que organiza suas experiências e conhecimentos, e assistemático, dado que tais 'organizações’ das experiências não visam a uma sistematização das ideias, nem na forma de adquirí-las, nem na tentativa de validá-las.

O tipo de investigação foi a pesquisa qualitativa, tendo como método a História de Vida. Duas palavras inglesas denominam a expressão "história de vida": story e history. A life story é a estória ou relato da vida tal qual foi vivenciada, sem confirmação da autenticidade dos fatos, pois interessa mais o ponto de vista do narrador. Por outro lado, life history, ou estudo de caso, é estudo sobre a vida de um indivíduo ou grupo de indivíduos, no qual são incluídos os relatos, documentos possíveis, entrevistas com pessoas, em uma mescla de "metodologias e métodos muitos diferentes, seja pela qualidade da presença do pesquisador na coleta de dados, seja pela análise dos materiais, seja pelo tipo de hipóteses científicas que ela verifica" (Cipriani, Pozzi, \& Corradi, 1985, p. 260). Neste artigo adotamos a segunda perspectiva de histórias de vida.

A história de vida possibilita que a essência subjetiva de vida de uma pessoa emerja, através dos relatos em primeira pessoa sobre a trajetória no âmbito das relações humanas, sendo uma maneira que aproxima pesquisadores e agentes sociais, dando-lhes papel ativo, sobretudo aos segundos, que refletem sobre sua própria vida.

Nesse sentido, e pensando que os relatos trazem conhecimentos populares manifestos por pessoas ligadas ao futebol de várzea em SGBR, escolhemos coletar os 
relatos através de entrevistas semiestruturadas com perguntas abertas (Moura \& Ferreira, 2005, p. 66), ou seja, aquela que

se apresenta sob a forma de um roteiro preliminar de perguntas, que se molda à situação concreta de entrevista, já que o entrevistador tem liberdade de acrescentar novas questões com o intuito de aprofundar pontos considerados relevantes aos propósitos do estudo.

Tal escolha se faz por aproximar-se mais da concepção de pesquisa ora explorada, na qual

a análise mostra antes que a relação (sempre social) determina seus termos, e não o inverso, e que cada individualidade é o lugar onde atua uma pluralidade incoerente (e muitas vezes contraditória) de suas determinações relacionais (De Certeau, 1998, p. 38).

Após a elaboração do roteiro de entrevista, procuramos discutir previamente como se dariam as entrevistas com os dois times de futebol de várzea aqui estudados. O critério para escolha dos entrevistados reuniu um conjunto de aspectos: o envolvimento com o futebol seja como jogador, torcedor ou dirigente; o desejo de contribuir com a pesquisa, pois foram consultados um número grande de agentes antes da escolha da amostra; a disponibilidade do entrevistado; a dificuldade em encontrar alguns integrantes que se mudaram de bairro ou de cidade e o fato de que alguns já tinham falecido. Além disso, com a análise das entrevistas, verificamos e chegamos ao "ponto de saturação", que é quando os assuntos parecem dar volta sobre si mesmo, e o entrevistador ter a sensação de esgotamento do assunto.

Combinamos, então, que a cada time seria dedicado um dia diferente, de maneira que começámos pelo time São Gonçalo Beira Rio e as entrevistas foram realizadas à beira do campo de futebol. No dia seguinte, visitamos os integrantes do Milionários Futebol Clube, sendo que nos deslocamos a vários lugares diferentes para encontrar um e outro. Ao todo, são onze (11) pessoas que contribuíram, sendo cinco de cada time de futebol e um entrevistado que, pego de surpresa, nos falou sobre o futebol mato-grossense em geral, sendo o relato deste último suprimido desta investigação por distanciar-se do objeto em pauta. 


\section{Investigação Sociológica sobre o Futebol de Várzea na Comunidade São Gonçalo Beira Rio em Cuiabá/MT}

Nas entrevistas semiestruturadas com perguntas abertas, facilitando as respostas em forma de relatos, as indagações foram feitas de maneira não padronizada, sendo mais espontâneas. Durante as entrevistas, coube ao entrevistador incentivar indiretamente, com monossílabos, evitando-se interferências nos relatos. Esses relatos foram agrupados em instâncias táticas de abordagem, cada qual trazendo uma temática distinta.

\section{APORTE TEÓRICO-CONCEITUAL}

Em A Invenção do Cotidiano (1998, p. 45), De Certeau apresenta um "método" de pesquisa inovador, o qual se intitula análise polemológica da cultura, considerando que "a cultura articula conflitos e volta e meia legitima, desloca ou controla a razão do mais forte". E sugere, quanto à análise das narrativas das práticas comuns, como as sobre o futebol de várzea coletadas nesta pesquisa: "introduzi-las com as experiências particulares, as frequentações, as solidariedades e as lutas que organizam o espaço onde essas narrações vão abrindo um caminho, significará delimitar um campo" (De Certeau, 1998, p. 35).

De Certeau (1998, pp. 18-9) busca a sua autonomia e liberdade, de maneira que:

Dir-se-ia que, sob a realidade maciça dos poderes e das instituições e sem alimentar ilusões quanto a seu funcionamento, sempre discerne um movimento brownniano de micro-resistências, as quais fundam por sua vez micro liberdades, mobilizam recursos insuspeitos, e assim deslocam fronteiras verdadeiras da dominação dos seres sobre a multidão anônima [...] é natural que ele concentre a atenção nos minúsculos espaços de jogo que táticas silenciosas e sutis 'insinuam'.

De Certeau (1998, p. 45) se interessa por diversas áreas, entrecruza métodos, "que pratica sem prestar vassalagem a nenhum dele, e pela diversidade de suas competências"; por isso mesmo, "intriga e desconcerta". Assim, ouvir os relatos orais de jogadores de futebol de várzea em SGBR introduz novos olhares dentro do campo investigado, no qual se buscam elementos de tensões que forneçam "equilíbrios simbólicos, contratos de compatibilidade e compromissos mais ou menos temporários", tendo-se o futebol de várzea como mediador dessas práticas.

Quais táticas delineiam as maneiras de fazer o futebol de várzea na comunidade São Gonçalo Beira Rio? Antes de uma abordagem específica, cabem algumas concei- 
tuações e diferenciações entre os termos "tática" e "estratégia". O termo tática é aplicado nas pesquisas de De Certeau (1998) como maneira de aproximação da problemática suscetível de articular o material coletado e a descrição de sua prática; nesta investigação, foi utilizado para a análise de dados coletados. “Tática”, do grego taktiké ou téchne, é qualquer elemento componente de uma estratégia, com a finalidade de se atingir a meta desejada em um empreendimento qualquer, sendo a estratégia a visão macro, sistêmica, de conjunto do empreendimento, segundo Koogan e Houaiss (1993, p. 815).

Se, por um lado, a tática se ocupa do microssistema, a estratégia abrange o todo desse conjunto de táticas. Nesse sentido, De Certeau (1998, p. 46) diz que a estratégia é "o cálculo das relações de forças que se torna possível a partir do momento em que um sujeito de querer e poder é isolável de um ambiente", ao passo que a tática é "um cálculo que não pode contar com um próprio, nem, portanto, com uma fronteira que distingue o outro como totalidade visível". A tática só tem por lugar o do outro" (De Certeau, 1998, p. 45, grifo nosso).

Tendo-se sempre em foco que a tática só tem por lugar o do outro, ela representa também a gama de ações ou maneiras de fazer o futebol de várzea, bem como outros esportes, o que insinua certo entrecruzamento metafórico na utilização de referidos termos dentro deste texto. Dentro do futebol amador, há uma tática de disposição em campo intitulada de "carrossel" ou "futebol total", em que todos os jogadores ocupam todas as funções e posições, indiferenciadamente, com exceção eventual do goleiro. Digamos, então, que os atores sociais aos quais pertencem os relatos orais colhidos são os jogadores, nesse campo social da comunidade SGBR, e nós, deste lado, intentamos apanhar as bolas jogadas nos diversos alvos.

Evidenciar as maneiras de fazer o futebol de várzea em SGBR requer, antes, considerar que "deve haver uma lógica dessas práticas" (De Certeau, 1998, p. 42); mais ainda, que nessas práticas culturais consideradas marginalizadas existem "operações dos usuários, supostamente entregues à passividade e à disciplina” (De Certeau, 1998, p. 37), operações ou táticas.

Assim sendo, consideramos aqui o futebol de várzea como produto cultural, emergido da vivência popular, passível de estudo, "daquilo que o consumidor cultural 'fabrica' durante a sua prática” (De Certeau, 1998, p. 39), ou, ainda, de como o seu consumo se prolifera nas relações sociais e culturais peculiares a cada região, bairro, campo de jogo, ou seja, de como se diferencia quando do uso, ou das suas práticas, ou maneiras de fazer. Nesse sentido, os jogadores do futebol de várzea, os espectadores 
da beira de campo de futebol, a comunidade e a sociedade em geral são consumidores cujas produções diferem e denotam, ainda, bifurcação que possibilita inúmeras interpretações. Pelo menos duas estão evidentes: a primeira refere-se à produção da imagem do futebol de várzea propalada, geralmente via senso comum e meios comunicativos - principalmente o rádio. A segunda vive na produção secundária que se esconde nos processos de sua utilização, havendo diferença ou distanciamento entre imagem e produção (De Certeau, 1998, p. 40).

Na comunidade SGBR, o futebol de várzea alcançou grande sucesso entre as décadas de 1980 e 1990, conforme constatamos nas narrativas colhidas na pesquisa. Dois times - São Gonçalo Beira Rio Futebol Clube e Milionários Futebol Clube - disputavam entre si, em quase todos os torneios, sendo este último dissidência daquele primeiro. Há também outro time, não investigado aqui, na comunidade de Carrapicho, localizada na outra margem do Rio Cuiabá.

Tem-se, então, o espaço dos campos de futebol de várzea como espaço de contradições, ou como nichos culturais, cujas maneiras de fazer "constituem as mil práticas pelas quais usuários se reapropriam do espaço organizado pelas técnicas da produção sócio-cultural" (De Certeau, 1998, p.41).

Esse espaço, com seu mapa, percursos e demarcações, evidencia modos de agir, astúcias de consumidores, que para De Certeau formam uma rede de antidisciplina, não se reduzindo a uma rede de "vigilância", pois jogar como os mecanismos da disciplina e não se conformar com ela constitui a contrapartida, "do lado dos consumidores (ou 'dominados'?), dos processos mudos que organizam a ordenação sócio-política” (De Certeau, 1998, p. 41).

Defendemos a hipótese de que o futebol de varzea é um elemento/fenômeno que atua como mediar cultural e que existema diversas maneiras de fazer o futebol de várzea em SGBR, em que "as operações multiformes e fragmentárias, relativas a ocasiões e detalhes" (De Certeau, 1998, p. 42).

As táticas de abordagem remontam às maneiras de fazer de cada time de futebol de várzea em SGBR. Tem-se a cultura do futebol de várzea como lugar enunciativo dos narradores. "Tática”, termo por nós escolhido, denota a intenção de dar voz ao outro, ou de considerar a contradição discursiva, levando em conta que "a tática só tem por lugar o do outro" (De Certeau, 1998, p. 46) e, que

Essas táticas manifestam igualmente a que ponto a inteligência é indissociável dos combates e dos prazeres cotidianos que articula, ao passo que as estratégias 
escondem sob cálculos objetivos a sua relação com o poder que os sustenta guardado pelo lugar próprio ou pela instituição.

As táticas dos relatos orais representam microdiferenças discursivas, que em conjunto formam bricolagem. Mosaico dinâmico, incerto, tentador e audaz que compõe este texto a partir do desconhecido, pois aglomera métodos, técnicas, teorias que nos dão as idiossincrasias, contradições dialógicas que esboçam as maneiras de fazer a cultura ora recortada.

Efetivamente, a moldagem dos relatos em táticas serviu apenas como base de 'consulta' às problematizações, aqui chamada de "estratégias". Estratégia é a combinação de elementos heterogêneos que, no dizer de De Certeau (1998, p. 46), é o "cálculo das relações de forças que se torna possível a partir do momento em que um sujeito de querer e poder é isolável de um 'ambiente"'.

Ramificamos as táticas em quatro rizomas multiplicadores (que, seguramente, se redistribuem e se bifurcam), sendo: a) Táticas Fundacionais, b) Táticas Organizacionais, c) Táticas Relacionais, e d) Táticas de Embate.

Esses percursos, então, supõem antes uma expressividade que faz território, sendo que "a territorialização é o ato do ritmo tornado expressivo, ou dos componentes de meios tornados qualitativos. A marcação de um território é dimensional, mas não é uma medida, é um ritmo" (Deleuze \& Guattari, 1998, p. 122). Assim explicitado, a seguir expomos as táticas elencadas acima.

Richard Giulianotti (2010), sociólogo do esporte, defende que o futebol passou até chegar ao formato atual, "por estágios específicos, que podem ser caracterizados como 'tradicional', 'moderno' e 'pósmoderno”.

Quando discuto o 'tradicional' estou falando sobre o 'pré-moderno', onde vestígios da era pré-industrial ou pré-capitalista são ainda muito influentes. De modo geral, isso envolve a aristocracia ou a classe média tradicional, que exerce sua autoridade muito mais por convenções do que por meios racionais ou democráticos. [...] A 'modernidade' está relacionada à rápida urbanização e ao crescimento demográfico e político da classe trabalhadora. Estabelece-se uma divisão entre espaços masculinos (público, produtivo) e espaços femininos (privado, reprodutivo). [...] O crescimento dos meios de comunicação de massa, as melhorias de infra-estrutura e a criação de programas de bem-estar social também servem para suscitar sentimentos unitários de identidade nacional. [...] Em 


\section{Investigação Sociológica sobre o Futebol de Várzea}

na Comunidade São Gonçalo Beira Rio em Cuiabá/MT

matéria de lazer e de recreação, a divisão entre burguesia e classes trabalhadoras é reproduzida por meio de uma diferenciação entre alta cultura ('legitimada') e baixa cultura ('popular'). [...] A 'pósmodernidade' é marcada pela dimensão crítica ou pela rejeição real da modernidade e de suas propriedades definidas. [...] As identidades sociais e culturais tornam-se cada vez mais fluidas e 'neotribais' em suas tendências de lazer. [...] A globalização dos povos, da tecnologia e da cultura dá origem a uma cultura híbrida e uma dependência econômica das nações em relação aos mercados internacionais (Giulianotti, 2010, p.9-10).

O livro Sociologia do futebol: dimensões históricas e socioculturais do esporte das multidões de Richard Giulianotti (2010) se tornou em uma referência bibliográfica fundamental sobre o futebol como fenômeno social moderno e contemporâneo, sendo que neste estudo nos interessa suas análises acerca da construção das rivalidades desportivas e futebolísticas e os processos de construção de identidades sociais, a integração social e o futebol como mediador cultural.

Giulianotti (2010, p. 26) destaca que o drama diático do futebol se expressa em vários níveis: países, times e jogadores. Cada jogador está comprometido com seu oponente. Os clubes de futebol estabelecem "identidades culturais por meio da rivalidade e da oposição. As mais puras rivalidades crescem entre clãs municipais”. No início da história do futebol a estratégia de criar dois times rivais em uma mesma localidade (cidade, estado ou região) foi fundamental para o sucesso deste esporte. Trata-se de um fenômeno que deu origem aos "clássicos" do futebol, como Roma-Lazio, Internacional-Gremio, Rangers-Celtic, etc. As rivalidades são reforças em termos de espaço, etnia, classe social, religião e outras categorias sociais.

Em "Le match de football: ethnologie d'une passion partisane à Marseille, Naples et Turin”, Christian Bromberger (1995a), apresenta uma importante contribuição antropológica sobre o fenómeno futebolístico actual. Destaca com propriedade a dimensão planetária deste esporte, sua linguagem universal e o crescente número de espectadores e praticantes (situado na ordem dos milhões de pessoas quando contabilizadas as audiências televisivas dos espetáculos esportivos).

$\mathrm{O}$ autor considera que existem ainda poucos estudos sobre o futebol baseados em pesquisas empíricas. Sua intenção era, na referida obra, preencher a lacuna mencionada. Para isso, utilizou-se de entrevistas com os adeptos dos clubes, de histórias de vida, observações, inquéritos por questionário. Bromberger (1995a) analisou os significados do fenómeno futebolístico, as motivações para sua efervescência colectiva 
e as modalidades de adesão ao esporte bretão. Com base na interpretação de Geertz sobre a briga de galos em Bali, Bromberger (1995b) nos apresenta um esquema geral de interpretação do futebol, tendo como material empírico os dados coletados em pesquisa de campo realizada entre os adeptos dos principais clubes sediados nas cidades de Marselha, Turim e Nápoles. Apresenta e analisa a ligação entre os torcedores com os seus clubes prediletos. Aborda o futebol como metáfora para entender diversas dimensões da vida social, da guerra, conflitos e identidades sociais.

$\mathrm{Na}$ análise sobre os tipos de torcedores presentes nos estádios de futebol, Bromberger destaca os tipos de associações de adeptos, a divisão dos espaços das arquibancadas, os critérios de escolhas das torcidas pelos lugares no estádio, constatando que a escolha destes não leva em conta apenas o valor dos bilhetes de entrada nos estádios, envolvendo também fortes sentimentos de pertencimento a um grupo de torcedores com identidades específicas.

Outro tema relevante tratado pelo autor é o futebol como ritual contemporâneo. Para Bromberger (1995a), uma sociedade narra muito a respeito de si mesma por meio de suas paixões coletivas. Elas explicitam formas de sociabilidade e as contradições presentes em nossa época, colocando em destaque o horizonte simbólico das sociedades modernas. Os esportes são dimensões e fenômenos reveladores do modo pelo qual as sociedades toleram e geram expressões de violência e emoções coletivas.

Faremos uso ainda de autores como Norbert Elias e John L. Scotson (2000), sobre os conflitos entre estabelecidos e Outsiders, para analisar os embates e conflitos entre os atores sociais que faziam parte dos times de futebol de várzea na CSBR.

No próximo tópico apresentaremos a análise das entrevistas realizadas na pesquisa de campo.

\section{O FUTEBOL DE VÁRZEA EM CUIABÁ/MT}

\section{A Fundação dos Times de Futebol de Várzea na CSGBR}

As Táticas Fundacionais se referem aos relatos sobre a fundação dos dois times - São Gonçalo Beira Rio Futebol Clube e Milionários Futebol Clube. Destacamos primeiramente que as incertezas das recordações são apenas tentativas de revisitar o passado, tendo-se o presente em evidência e o devir dessas impressões. Memórias e confissões se enchem de imagens que se entrecruzam, posto que 


\section{Investigação Sociológica sobre o Futebol de Várzea \\ na Comunidade São Gonçalo Beira Rio em Cuiabá/MT}

As lembranças não são confiáveis, mas, por outro lado, pode ser a maneira pela qual essas memórias chegam à nossa imaginação, confundidas pois com pensamentos, ideias, sensações ligadas a outras memórias e outras sensações (Caballé, 1995, p. 109).

Entre os onze entrevistados na pesquisa, apenas os dois mais antigos relataram sobre a fundação do time São Gonçalo Beira Rio Futebol Clube, havendo começado na década de 1960, e os entrevistados do time Milionários Futebol Clube nada mencionaram sobre o assunto. Curiosamente, estes últimos são dissidentes daqueles primeiros, portanto, alguma história poderia ser aventada, algo que não ocorreu. As memórias e dissidências sobre a fundação dos clubes constituem importantes elementos da construção das rivalidades e identidades futebolísticas (Bromberger, 1995a; Giulianotti, 2010).

Entretanto, sobre a história de fundação do Milionários Futebol Clube quase todos os entrevistados sabem alguma coisa. Os narradores ou entrevistados que nada disseram são aqueles mais velhos, que acompanharam o São Gonçalo Beira Rio Futebol Clube de há tempos.

Dos relatos, consta que Milionários Futebol Clube nasceu da dissidência que houve dentro do time São Gonçalo Beira Rio Futebol Clube. Com variações nos relatos, tem-se que foi feita uma lista com o nome dos jogadores mais velhos do time, e essa lista foi aposta na parede para que ficasse visível a todos: “aí escreveu numa parede lá os nome das pessoas que eles não queriam mais no futebol deles", diz o Narrador 8, informando que aqueles jogadores foram considerados inabilitados para continuar no time, ou pelo avanço da idade, ou pelo rendimento em campo. Revoltados com a situação, resolveram, a partir daí, criar outro time. As memórias e dissidências sobre a fundação dos clubes constituem importantes elementos da construção das rivalidades e identidades futebolísticas (Bromberger, 1995a; Giulianotti, 2010).

Sobre denominação dada a "Milionários", são seguintes as narrativas, controversias:

1. Esse Milionário foi fundado por Grauco. (Narrador 2)

2. É o seguinte nóis começamos com o Milionário que a minha família jogava no São Gonçalo Beira Rio [...] agora nóis vamo fundá o time do Milionário, do time dos enjeitado aqui da comunidade. (Narrador 8)

3. [...] ficaram revoltados e resolveram se juntar e formar uma nova equipe na 
qual eu e o finado Valdir fomos presidente do Crube, que nós fomos fundador do Milionários, que nós que começamos o primeiro Milionários que naquela época era só um junta junta de pessoas que formaram, que formou um time e com o passar dos anos depois mais ou menos três anos de fundação aí surgiu o Milionários mesmo (Narrador 11)

Quanto ao nome dado ao time do SGBR, o Narrador 1 diz: “[...] e ali pra 64, 65 [...] nós pusemos uma diretoria que falava São Gonçalo, o gigante Beira Rio". Sobre o assunto, houve apenas essa narrativa. Por outro lado, sobre a criação do nome Milionários, foram registradas três narrativas, entre elas havendo controvérsias.

As versões apresentam que:

1. Foi da cabeça. Foi da cabeça que eu tirei. (Narrador 8 , Tática I)

2. [...] Nóis achamo o nome, por que nóis não podia por o nome de São Gonçalo... aí o Cráudio, um rapaiz que tinha loja aqui no Coxipó disse vamo arrumá um time pra nóis jogá.. [...] aí tem que por nome de time... aí a turma começo falá que tem tanta gente rico no time... brincadeira NE... ah! Vamos por Milionários e fico. (Narrador 9)

3. [...] Era camisa do Framengo só que tava escrito Milionário... intão um certo tempo aí... os reserva ficaram murdido aí emprestaram minha camisa, a camisa do Framengo.. intão falaram vamo monta um time co esse nome só pra brincá e com isso chegaram lá e arrumaram o time do...do Milionário. (Narrador 2)

As tensões narrativas apresentadas, em se pensando o futebol de várzea como mediador cultural. Os conflitos, as rivalidades e as oposições entre equipes de futebol representam dramas sociais vivenciados por grupos, classes sociais e nações, conforme Bromberger (1995a) e Giulianotti (2010) e fazem parte da história do futebol, considerando sempre as especificidades locais, regionais e nacionais.

Ampliando o quadro das microdiferenças para o cenário nacional, pode-se observar que o "auge" da disputa dos times São Gonçalo Beira Rio e Milionários deu-se em um período diacrônico em que o futebol profissional da Seleção Brasileira chegou às quartas de final da Copa do Mundo FIFA, em 1986, sendo derrotada pela França; despontou com o título de tetracampeão na Copa Mundial de 1994; ganhou ainda em 1989, 1997 e 1999 a Copa América e em 1997 ganhou a Copa das Confederações. Esse momento histórico do futebol de várzea em SGBR correspondeu, no esquema 
analítico de Giulianotti (2010), à fase moderna, quando se consolida a identidade futebolística daquela comunidade.

Seguramente, esses estímulos se refletiram nas maneiras de fazer o futebol de várzea em muitas comunidades ou bairros brasileiros, (re)surgindo times cuja aparente vontade de nacionalidade ressoou como continuidade da tradição que é o futebol enquanto cultura no Brasil.

Voltando ao cenário local da comunidade SGBR, podemos ler em sua história as diversas crises socioeconômicas, advindas do distanciamento do bairro São Gonçalo, situado à margem do Rio Cuiabá, cujo acesso tornou-se mais fácil no início da primeira década deste Século XXI. As atividades econômicas principais desta comunidade eram a fabricação artesanal de cerâmicas e utensílios, a agricultura de subsistência e a pesca, sendo que esta se deteriorou dadas a poluição e a instalação de dragas ao longo do Rio Cuiabá.

Na década de 1990, sobreveio nova crise, já que os produtos artesanais não tinham meio de escoamento e a comunidade não possuía qualificação técnica para enfrentar o mercado competitivo que despontava. Essa crise chamou a atenção do poder público e da sociedade civil que passou a revitalizar e (re)valorizar o patrimônio cultural daquela comunidade, como o siriri, o cururu e a pesca.

O futebol de várzea na comunidade SGBR foi reinventado dentro da crise, talvez como maneira de combatê-la, de fazer mais forte a identidade local ou de deixar emergir a alteridade existente e antes velada. Reinventar o futebol de várzea, através da criação de um novo time, nascido da rejeição manifesta de membros da própria comunidade, representa o embricamento entre futebol e cultura (Bromberger, 1995a).

Se, por um lado, houve essa identificação com o futebol nacional, naquele bairro as diferenças começaram a vir à tona, através da crise dentro do único time existente, o São Gonçalo Beira Rio. A partir do instante em que alguns jogadores foram "desligados" da equipe, sem a presença de diálogo prévio, conforme se constata, temos então a criação do novo, surgido da minoria marginalizada pelos pares do futebol de várzea. Como lembra Giulianotti (2010, pp. 25-30), as rivalidades locais foram relevantes na popularização do futebol e na criação de vínculos afetivos entre os indivíduos e os clubes/times de futebol.

Como começou a história dos dois times? Quem está falando a verdade? Aliás, o que é a "verdade"? Distante do propósito historicista, de registrar diacronicamente esses "fatos", interessa-nos mais compreender que aqueles narradores, cada qual apresenta a "sua" verdade, havendo se apropriado da história que se faz ambivalente. 
Os relatos denotam as diferenças nas maneiras de fazer. As contradições surgidas antes, durante ou depois da criação do Milionários Futebol Clube. Demarcações de territórios que ultrapassam o campo esportivo e se entrecruzam com as diferenças sociais, ali existentes. Dentro daquele mapa, podemos visualizar que as casas situadas mais próximas do campo do Milionários denotam melhor condição econômica de seus moradores, com fachadas mais modernas, maior planejamento arquitetônico, maiores terrenos, com carros mais modernos (Bromberger, 1995a).

Contrariamente, à medida que vamos adentrando na comunidade, as casas ao redor ou perto do campo do São Gonçalo Beira Rio são mais antigas, algumas conservam arquitetura de antigo modelo "cuiabano", quase inexistindo muros para dividir os terrenos. Precisamente nesta parte, a produção da cerâmica, a manutenção do folclore, do siriri e do cururu, bem como a concentração das peixarias são muito maiores e mais evidentes. Verifica-se a relação entre futebol, artesanato, dança, tradição e culinária, sendo o esporte bretão o elemento mediador.

Outra diferença, aqui já comentada, está na disposição e estrutura dos dois campos de futebol: o campo do Milionários localiza-se ao lado da avenida principal de acesso à comunidade; e o campo do SGBR situa-se no centro de um grande terreno público, rodeado por casas e quintas que se delimitam com o campo.

Essas diferenças socioeconômicas trazem implícitas expressões ou formações discursivas: "o expressivo é primeiro em relação ao possessivo, as qualidades expressivas ou matérias de expressão são forçosamente apropriativas, e constituem um ter mais profundo que o ser" (Deleuze \& Guattari, 1998, p. 123). Dito de outra maneira, as discrepâncias visíveis em aspectos econômicos evidenciam conflitos arraigados e constituem as diferenças socioculturais que, levadas para dentro do campo, fazem do futebol de várzea o mediador das relações sociais e dos problemas locais.

É no campo de futebol de várzea que as diferenças se exacerbam. Os relatos estampam que todo ressentimento ou dissensão afetiva ganha vazão durante o jogo, em que gritos, gestos bruscos, palavrões, duras vozes de comando trazem subliminarmente a mensagem de uma luta de poderes pela manutenção da supremacia de um time sobre o outro, como extensão rizomática de outras diferenças ali existentes, porque ali "há um equilíbrio instável de poder, com as tensões que lhes são inerentes" (Elias \& Scotson, 2000, p. 23).

Norbert Elias e John L. Scotson, em Os estabelecidos e os Outsiders: Sociologia das relações de poder a partir de uma pequena comunidade (2000), evidenciam em seus estudos os confrontos nas relações de poder entre moradores antigos de uma comu- 


\section{Investigação Sociológica sobre o Futebol de Várzea na Comunidade São Gonçalo Beira Rio em Cuiabá/MT}

nidade, os "estabelecidos", e aqueles que vieram depois, estrangeiros ou não, chamados de outsiders ou forasteiros. Para os autores, há uma evidente estigmatização que sobrepassa o campo socioeconômico e chega aos valores da autoestima daqueles que são "inferiorizados", conforme se lê no fragmento abaixo:

[...] Os grupos mais poderosos, na totalidade desses casos, vêem-se como pessoas 'melhores', dotadas de uma espécie de carisma grupal, de uma virtude específica que é compartilhada por todos os seus membros e que falta aos outros. Mais ainda, em todos esses casos, os indivíduos 'superiores' podem fazer com que os próprios indivíduos inferiores se sintam, eles mesmos, carentes de virtudes - julgando-se humanamente inferiores (Elias \& Scotson, 2000, p. 20).

Os autores chamam a atenção para a estigmatização coletiva, não específica de um ou outro membro, como é o caso da disputa de poder entre os times Milionários e São Gonçalo Beira Rio. Contudo, observamos que o este último time, formado por antigos moradores, não é aquele que se sente "superior" nessa relação. Contrariamente, ao time Milionários se tem atribuído o status de "vitorioso", posto que venceu nas disputas em campo, em quase todas as partidas entre os dois clubes. Conforme Giulianotti (2010, p. 26), "Os significados dessas rivalidades do futebol tenderam a ser corroborados por divisões históricas e culturais mais profundas. [...], a oposição é reforçada por chauvinismos locais que são mapeados em termos espaciais". Curiosamente, nos dias atuais, há uma espécie de reviravolta nesse jogo social, posto que os moradores da parte de baixo da rua, os menos favorecidos financeiramente, são os que mantêm restaurantes, os artesanatos de cerâmica e as danças populares da comunidade.

Parece evidente a interdependência que mantém as relações culturais, intermediadas pelo futebol de várzea em SGBR. Ou seja, "um grupo só pode estigmatizar outro com eficácia quando está bem instalado em posições de poder das quais o grupo estigmatizado é excluído" (Elias \& Scotson, 2000, p. 23).

Consideramos que a criação do time Milionários foi uma resposta à afronta recebida. Aqueles jogadores foram desterritorializados, marginados. Os discursos daí originados buscam uma reterritorialização, em forma de resistência à opressão sofrida. Buscaram, assim, a mesma via de (re)acesso: o futebol de várzea. Poderia ter sido outra a forma de resposta, mas é justamente ele, o futebol de várzea, que vai mediar essas diferenças, tornando-se um percurso cujos movimentos, ou táticas, formam um 
conjunto de estratégias contra a situação dada e com vistas à demarcação territorial naquele mapa (Giulianotti, 2010).

O motivo territorial de exclusão formou personagens rítmicos, e os contrapontos territoriais formam as paisagens melódicas. Temos, então, narradores que saem do anonimato e assumem para si a autoria de um feito que, por ser antitético, transgride regras sociais. Agora são dois os times, duas forças antagônicas que se completam em uma contradança forçada. São dois times dividindo o pequeno espaço que é a comunidade SGBR e demarcando seus territórios repletos de diferenças. Cabe aqui lembrar novamente Giulianotti (2010) quando argumenta que as rivalidades futebolísticas têm dimensões territoriais, étnicas e culturais.

Trata-se de uma redistribuição do espaço, e "ali ela cria ao menos um jogo, por manobras entre forças desiguais e por referências utópicas" (De Certeau, 1998, p. 79).

$\mathrm{Na}$ inventividade do cotidiano, tem-se o futebol de várzea como mediador de um conflito, ou, mais ainda, como mote principal de sua exacerbação. Nesse sentido, vale destacar o que se instala em cada fala, considerando-se que essas táticas de recontar a história da fundação dos times são

Mil maneiras de jogar/desfazer o jogo do outro, ou seja, o espaço instituído por outros, caracterizam a atividade, sutil, tenaz, resistente de grupos que, por não ter um próprio, devem desembaraçar-se em uma rede de forças e de representações estabelecidas. Tem que 'fazer com'. Nesses estratagemas de combatentes existe uma arte de golpes, dos lances, um prazer em alterar as regras de espaço opressor. Destreza tática e alegria de uma tecnicidade (De Certeau, 1998, p. 79).

Se, nos dizeres de Deleuze e Guattari (1998), o território é primeiramente a distância crítica entre dois seres da mesma espécie para marcar suas distâncias, temos que os dois times buscarão maneiras de fazer a coexistência de seus membros, configurando uma paisagem melódica daquela comunidade, paisagem repleta de contrapontos complexos.

À medida que avancemos na análise dos relatos, as diferenças mediadas pelo futebol de várzea terão contorno mais evidente. Vimos, por exemplo, que aqueles jogadores rejeitados ou excluídos deram novo ritmo às maneiras de fazer esse esporte no SGBR. Onde começam os rastros? Para onde nos levarão? São muitas as pegadas, e múltiplos os caminhos dentro desse campo, de maneira que deixaremos o futebol de várzea, esse mediador, ir se insinuando por onde nos é possível caminhar, correr, parar, retomar, enfim. 
Quem começou o quê? Inexistindo uma história "oficial", o que temos é um torneio de relatos, com alguns narradores em campo assumindo o feito do gol que é a criação do Milionários e havendo, inclusive, a possibilidade de dois tempos: o primeiro e o segundo Milionários, como se pode observar nos fragmentos destacados (Benitez, 2014).

Observamos que dentre os relatos colhidos nas entrevistas, todos os atores que contribuíram tendem a falar mais do time Milionários do que sobre o time São Gonçalo Beira Rio, evidenciando relativo domínio daquele primeiro sobre este, principalmente levando-se em consideração quantitativa o número de vitórias de ambos. Milionários venceu mais vezes o São Gonçalo Beira Rio em suas disputas diretas.

\section{A Organização dos Times de Futebol de Várzea na CSGBR}

As Táticas Organizacionais reúnem relatos sobre como cada time se articulou para organizar-se, enquanto equipe de futebol de várzea, em seus aspectos diretores, de torcida, de formação da ala feminina, equipe técnica, locomoção para participar em outros bairros, alimentação, entre outros. Como demarcação dos percursos, cada narrador nos falou especificamente sobre o time do qual fez parte, como se as memórias lhes servissem de autoproteção ou defesa em campo.

Acerca dos pontos em comum, entre os dois times, destacamos os seguintes fatos: existiu a liga LCB - Liga de Campeonatos dos Bairros; os dois times tiveram composição de respectivas diretorias; as categorias existentes se chamavam de aspirante e de titular; os torneios aconteciam durante o dia todo; quase inexistiam treinos; as mulheres (geralmente esposas) desempenhavam tarefas secundárias, mas imprescindíveis, de auxílio aos times, como lavar uniformes e levar água de beber, entre outras.

Além disso, havia responsáveis pelo cuidado e marcação dos campos de futebol de várzea; após os jogos havia formas de comemoração; todos colaboravam nas cotas financeiras para pagar árbitros e outras necessidades do grupo. De discrepante, e que chama a atenção, tem-se que o time São Gonçalo Beira Rio era formado exclusivamente por moradores da comunidade, ao passo que no Milionários participavam jogadores de diversos bairros, revelando diferenças sociais e espaciais na formação dos times de futebol e dos torcedores (Bromberger, 1995a; Giulianotti, 2010).

Entre os seis narradores do time São Gonçalo Beira Rio não houve relatos sobre a escolha de técnicos. No Milionários, contrariamente, há o registro de que "às vezes era meu marido, às vezes era seu Aquino que vinha ajudar também, mas no mais 
era só jogador" (Narrador 8). Esse narrador (8) é uma mulher; ela foi presidente do Milionários por quase vinte anos; seu esposo foi técnico e jogador e seu filho joga futebol, ainda hoje.

1. Eu arrumava água, arrumava gelo, era água gelada, não era quente não [...] tinha vez já entrava com sete jogador e eu zangava demais, xingava jogador [...] (Narrador 8)

2. Ela fazia tudo, teve veis que ela comprô até uniforme, trabalhô assim, empregada na Coophema, comprô unifore com o dinheiro dela, ela fazia tudo, lavava roupa tudo [...] e ela tinha veiz que ajudava, tava meio apertado pra pagá juiz arguma coisa, ela tinha dinheiro ia dá... ia assim.. (Narrador 9)

3. A dona Pedrosa... era a comandante de tudo, né? Ela enfrentava os jogadores adversários como se fosse mãe da gente... então ela protegia a gente, botava a mão na cara, quando precisava ela xingava e então a gente se sentia filho deles [...] (Narrador 10)

Antes de prosseguir, ressaltamos que, após a criação do time Milionários Futebol Clube, o São Gonçalo Beira Rio Futebol Clube dificilmente ganhou nos embates entre essas duas equipes. Milionários convidava muitos jogadores de fora para tomar parte no time. Vitórias e derrotas acentuaram os confrontos e foram dando ritmo mais forte, de competitividade, como se um desvão começasse a esboçar a fronteira entre os dois territórios, demarcando os discursos e as maneiras de cada time fazer o futebol de várzea.

Havia, nos dois times, uma maneira diferente de se fazer o futebol de várzea? Seguramente. Evidentemente. Comecemos, então, pela latente diferença na constituição de ambas as equipes. Se, por um lado, o São Gonçalo Beira Rio resistiu às mazelas do cotidiano, buscando manter como jogadores apenas os moradores daquela comunidade, contrariamente a tática do Milionários foi buscar reforços nos campos vizinhos, como se pode observar no seguinte relato:

[...] O nosso, Milionários sempre teve jogadores de outros bairros, o time aqui do... daqui do São Gonçalo ele era mais bairrista. Ele era mais tradicional e o time do Milionários era mais...liberal. (Narrador 10).

Secular embate entre conservadores e vanguarda, entre os estabelecidos e os outsiders, diriam Elias e Scotson (2000), evidente no âmbito de todas as artes e em todas 
as manifestações culturais existentes. Do ponto de vista tático, São Gonçalo Beira Rio e Milionários mantiveram o foco centrado na meta desejada de firmar-se como time de futebol de várzea, dentro da comunidade SGBR, bem como dentro do município de Cuiabá e do estado de Mato Grosso.

Evitando taxar de maneira incisiva que as derrotas sofridas pelo São Gonçalo Beira Rio advêm da escolha por manter-se dentro da conservação "bairrista", termo usado pelo Narrador 10, preferimos admitir maneiras de lidar deliberadamente com a vida, de imaginar a organização social como marco de resistência, cujo vetor futebol de várzea, enquanto instrumento, vem mediar diferenças nos campos financeiro, político, ideológico, acional, construindo formações sociais. O futebol aqui certamente expressou contradições, rivalidades e emoções coletivas (Bromberger, 1995a).

Então, através das maneiras de fazer o futebol de várzea, este arbitra sentidos, sentimentos, expressividades que emergem, talvez desde há muito guardados ou calados, e que são deslocados para dentro do campo, para a sua beira, que é ocupada pelas torcidas, e para dentro das casas, espaços intimistas onde supomos diálogos mil sobre essa rivalidade.

Milionários adveio de um processo de desavenças e conflitos sociais daqueles jogadores excluídos do seio "tradicional, familiar" do futebol de várzea de SGBR. Essa experiência possibilitou-lhes transformar a estratégia crítica. Desse modo, foram do pertence ao não-pertence, vivenciando o

lidar com a cultura como produção irregular e incompleta de sentido e valor, freqüentemente composta de demandas e práticas incomensuráveis, produzidas no ato da sobrevivência social (De Certeau, 1998, p. 240).

Discussões sobre deslocamento espacial levam-nos à ideia de Deleuze e Guattari (citado por Mostafá \& Nova Cruz, 2009, p. 29) de "todo um novo mundo possível". Sentindo-se fora de campo, sem o território de origem, aqueles jogadores, movidos pelo desejo de continuarem jogando futebol de várzea, reterritorializaram o espaço desse espaço naquela comunidade. Assim, fazendo-o, incidentalmente, talvez, tenham se liberado da "única ordem possível estabelecida", indo ao encontro do Outro, esse Outrem deleuziano que possibilita "a nova visão de que não há nem sujeito, nem objeto e sim relações, encontros” (Mostafá \& Nova Cruz, 2009, p. 31).

Resultou, daí, talvez como tática organizacional, a posse de uma mulher como presidenta do time Milionários, dona Marli Alves da Silva, a dona Pedrosa, represen- 
tação de uma transgressão de regras esportivas e sociais, em confronto direto com a organização até então delegada a um homem, dentro da cultura popular das maneiras de fazer o futebol de várzea no Brasil. Por suposto, não é a única nem a primeira mulher a exercer essa função. A presença ativa da mulher à frente de um time de futebol cria impactos mediados pelo próprio futebol.

Naquela comunidade, berço da cultura mato-grossense, considerando-se aquelas décadas em que dona Pedrosa dirigiu um time, é relevante essa manifestação que se faz subversora dos padrões de cunho eminentemente patriarcal, maneira que desloca e inverte papéis sociais, que insere a mulher nos fazeres mais diretos no campo do futebol de várzea. Trata-se de rizoma que vai bifurcando as atuações e seus reflexos socioculturais porque a atuação feminina em espaço eminentemente patriarcal surge como "uma possibilidade virtual, retirada do caos possível, trazida por outrem, atualizada no real, em uma mudança absoluta do pensamento" (Mostafá \& Nova Cruz, 2009, p. 31).

Dito isto e descartando quaisquer intenções de cunho estruturalista em evidenciar as ações binárias do papel feminino, e, paradoxalmente já o fazendo, por ser algo que se multiplica, desse confronto entre os dois times surge também outro conflito que provoca um deslocamento da mulher no espaço, ou de suas funções dentro das equipes. Ela, dona Pedrosa, também é desterritorializada: de prestadora de serviços básicos, como lavar uniformes e servir água gelada, ela se reterritorializa ocupando papel principal dentro desse embate, colocando-se à frente, na defesa de seu território, buscando circular em nível de igualdade dentro daquele mapa, demarcando fronteiras através do percurso que vai desenhando as "trocas sociais, estilos de invenções técnicas e um estilo de resistência moral" (De Certeau, 1998, p. 88).

Nesse processo organizacional de cada time, as maneiras de fazer são esquemas de operações táticas, segundo De Certeau. Narrador 8, a mulher, protagonista no papel de presidenta do time organiza, incentiva, se engaja na luta contra o time a que pertenceram ela e seu esposo, desdobra-se em mil funções, contrapõe-se, primeiramente, ao que considera "traição" contra aqueles jogadores excluídos; depois, aceitando e convidando "intrusos" para formarem parte da equipe do Milionários e, por último, adotando e quiçá apropriando-se do time, fazendo dele "sua casa, sua vida". Para Giulianotti (2010, pp. 26-27), "As rivalidades entre dois clubes permanecem a norma na maioria das cidades, com dimensões espaciais que servem mais uma vez para fortalecer as oposições. [...] A rivalidade entre Roma e Lazio reflete as diferenças culturais entre a Cidade Eterna e a região rural que a cerca". 
Seguramente a técnica de ambos os times careceu, dentro de um planejamento estratégico elaborado, de uma visão racionalizada. Mas é essa maneira de fazer, artesanal, improvisada, (re)inventada cotidianamente, que insinua o devir do próprio sujeito e do objeto naquele espaço. É o povo marginalizado articulando-se com outros povos de outros bairros, em condições talvez idênticas ou piores, fazendo o nome da comunidade e atraindo, como consequência, olhares convenientes e ambiciosos que passaram posteriormente a investir naquele bairro estrategicamente político.

Outrem, ou o Outro, o estrangeiro que vem ocupar esse território dado e povoado, surge não para resolver os problemas, mas para evidenciá-los, para colocar à mesa, ou em campo, um jogo escondido de relações sociais em que todos são protagonistas; nem ganhadores, nem perdedores, jogadores somente.

No próximo item analisaremos o futebol como elemento produtor de relações e padrões de interação social.

\section{Interações e Relações no Futebol de Várzea na CSGBR}

As Táticas Relacionais contêm seleções de relatos sobre a interação dentro de cada time e em relação aos demais, de outros bairros, principalmente na participação em torneios e campeonatos, festas de confraternização, entre outros. Os narradores que contaram sobre o time São Gonçalo Beira Rio disseram que participaram de vários campeonatos no bairro e fora dele:

1. Nosso time era um time respeitado. Jogava no Pico do Amor, tinha muitos times. Nosso time era um time respeitado, jogava no Pico do Amor, tinha muitos time.. Esperança... é... Esperança, Vila Nova do Quebra Pote, Bom Sucesso ... é... Lavrinha, Olaria. (Narrador 10)

2. Em 95, 95 nóis fomo jogá lá no Jatobá e alugaram pra nóis uma tombera... Garimpo Jatobá. (Narrador 2)

3. A história que eu alembro ainda de um campeonato da LCB que nóis disputamo... nóis tinha um time imbative aqui e fomo disputá lá e incrusive eu feiz um gol do título. Fomo campeão [...] (Narrador 3)

O futebol possui também a semântica da solidariedade social. Segundo Giulianotti (2010, p. 31), ordem social, solidariedade e continuidades políticas são fundamentais para entender a sociedade do ponto de vista durkheimiano. "A formação dos clubes 
de futebol e a associação constante e voluntária de tordedores e de jogadores ajudam a contrabalançar os sentimentos de atomização e de alienação que corrompem indivíduos nas grandes e impessoais cidades". Os que se integram aos clubes de futebol se situam em um sistema social mais amplo. O futebol ajuda a promover formas mais profundas de identidade e solidariedade em diferentes níveis.

4. Década de 90, noventa foi um ano muito bom pro São Gonçalo Beira Rio, nós disputamo vário campeonatos, em oitenta teve um campeonato muito bom da copa kaiser [...] teve o desafio dos 10 que o São Gonçalo participou e aquele tempo era times de várias regiões [...] (Narrador 4)

5. [...] O futebol aqui era bão demais, todo sábado, domingo lotava. O bairro inteiro tava torcendo aqui, ajudava [...] (Narrador 6)

Por outro lado, os relatos sobre o Milionários, são os seguintes:

6. [...] Nóis jogava prá fora, ia no Craudio Kieski ... uma veiz ele veio aqui, o juiz fez uma bagunça conosco aqui, né ... aí nós zangamos com ele, aí eu já queria partir pra ignorância porque eu sou meio da pá virada mesmo, né.. O Milionários ... ora, eu vou falá a verdade pro cê... representô muitas coisas, representô muito... eu peguei muitas amizades, amizade boa, amizade mesmo, honesta, você sabe que até hoje eu tenho muitas amizade através do... do jogo. (Narrador 8)

7. [...] Nóis travessava o Rio Cuiabá pra ir jogá lá no campo do Lutinho ... jogava no São Francisco... Verdão, por tuda parte [...] eu saí dali um dia pra jogá num tar de São Simões em Várzea Grande ... uma veiz nóis tivemo num torneio aqui vinte e quatro equipe ... fico falado na rádio, tudo mundo queria vim... aí minha esposa fez duas panelona de carne cóarroiz, carne seca co arroiz e farofa de banana, e aí feiz uns dois pacu que Kaicedro tinha dado ... nóis ganhamo no pênalti e aí foi pra decisão e nóis ganhamo o jogo, né... (Narrador 9)

8. Tem várias histórias muito interessantes do.. do.. não só dentro de campo mas extra campo que era o convívio com eles... é, após jogo a gente senta, conversa, chora ou ri, se era vitoria ou derrota .. com a amizade que a gente tinha.. ajudava e quando precisava a gente viajava pros bairros.. a gente ia jogar em Várzea Grande, Santo Antônio... todo mundo alegre, todo mundo participava, soltava foguete. (Narrador 10) 
9. Nós ganhamos um dos títulos mais importantes, portanto Cuiabá estava completando 250 anos, então foi assim uma grandeza pro bairro São Gonçalo ... uma veiz fomo jogá lá no Pico do Amor que o transporte do time foi... levaram numa caçamba e o motorista não sei o que ele arrumou que levantou a caçamba e quase que derrubo todo mundo... a gente sempre... aquela época o trânsito era livre, você podia transitá com caminhão carregano pessoas [...] (Narrador 11)

Os relatos acima mostram como o futebol mediou as relações sociais naquela comunidade, gerando diferentes padrões de interação social e de solidariedade, o que nos permite retomar Giulianotti (2010, p. 31), quando defende que "todos os clubes são denominados simbolicamente de acordo com um "local" particular e, assim, têm o tipo de laço afetivo com uma localidade específica, que encontramos em sociedades mais tradicionais e localistas. Os jogadores também podem ser fortes torcedores do clube, morar perto do campo de futebol e compartilhar um orgulho chauvinista com a comunidade".

Considerando-se a história sobre o surgimento do futebol no Brasil, que começou pela várzea, tendo sido a primeira partida realizada em abril de 1895, conforme referências de Azevedo (2006, p. 03), e ainda que o futebol de várzea em seu início "foi discriminado e repreendido até mesmo pela polícia, [pois] era considerado um encontro de vadios, desordeiros e indisciplinados", queremos explorar a ludicidade dos campos de várzea enquanto constituinte do homo socius, na busca de novas formas de sociabilidade e de agrupamento.

No início do Século XX, segundo relata Dumazedier (1975, p. 47), em razão direta da expansão da industrialização e da urbanização, proliferou a convivência social através de bares, cafés, sendo, "no entanto, as organizações recreativas e educativas a forma mais original de sociabilidade desenvolvida pelo lazer". Ainda em Dumazedier $(1975$, p. 49) lemos que

O conjunto dessas associações de todos os tipos forma, em princípio, um quadro de trocas frutíferas entre pessoas de situações sociais e de nível de instrução diferentes. Não há dúvida de que a tendência geral das organizações de lazer tende a uma unificação dos gêneros de vida.

Associações de lazer influem no modo de vida do bairro ou comunidade, e o modificam, agregando ou desagregando grupos. Desagregam quando criam sociedades 
fechadas sobre si próprias e agregam quando grupos afins se identificam com aquele presente, que tendem a plasmar, na indiferença em relação ao futuro. São os novos tipos de sociedades utópicas que, acima das diferenças de classe ou posição social, se buscam em nome do "bem comum", "orientando-se na direção de um universo semi-real, semi-imaginário, onde o homem pode subtrair-se das suas relações com a humanidade" (Dumazedier, 1975, p. 49).

A euforia ou a decepção compartilhada antes, durante e após o jogo de futebol de várzea oferece aos times essa possibilidade de um espaço outro, distante da realidade cotidiana, encontrando-se com seus pares nos diversos bairros praticantes dessa modalidade de lazer esportivo. Será o lazer o novo ópio do povo? - indaga Dumazedier (1975, p. 50).

Há um fortalecimento do padrão "um por todos", do comunitarismo que pede o sacrifício em nome do grupo ou time. O futebol como elemento produtor de solidariedade mecânica.

O futebol de várzea tornou-se, então, o lazer preferencial daquela época, do tempo de fortalecimento da identidade daquela comunidade, maneira de fazer a padronização de comportamentos, tanto que a criação de um novo time composto por jogadores "estranhos" ao meio causou indignação dentro do time tradicional, mais antigo. Choque cultural, conflitos estabelecidos, laços sociais ameaçados, desconstrução e devir. O que há de vir? Sair para participar em torneios e campeonatos fora da comunidade SGBR poderia ser visto como busca de fortalecimento de um "nós" comum, busca das maneiras de fazer táticas diferentes, mantendo-se as estratégias gerais. Essa saída também foi vista como procura de novos desafios, novos embates, novas maneiras de fazer, mimeticamente reproduzidas nos costumes, como o de providenciar transportes precários e arriscados. Não havia o rigor atual da cobrança das leis de trânsito, o que não impedia o transporte irregular de pessoas sobre caminhões, basculantes etc. Mas o risco era evidente. Todos os times se arriscavam, a seu modo. Inventavam-se, no afã de sair e participar, maneiras de fazer viável o transporte de jogadores e torcidas.

Pensemos, antes de sujeitos e objetos, o espaço esvaziado, ocupado, reocupado, novamente esvaziado. Pensemos que, além do tempo, é no espaço que as relações sociais acontecem. Esse espaço é habitado pelo devir, pela incógnita permanente sobre o próximo passo: "Não é mais o tempo que está entre dois instantes, é o acontecimento que é um entre-tempo" (Deleuze \& Guattari, 1998, p. 203, citado por Mostafá \& Nova Cruz, 2009, p. 94). 
O duplo do espaço e do tempo. Do espaço território-comunidade SGBR, cujo movimento socioeconômico se estanca quando as produções artesanais e a pesca sofrem baixas na procura; espaço que simboliza a vitória do tempo sobre o lugar. E o outro espaço, ou o espaço do Outro, espaço desterritorializado, desconhecido, ocupado como forma de vazão ao impacto da crise, significando a vitória do lugar sobre o lugar, pedindo movimentos, maneiras de fazer o futebol de várzea, o lazer que escala por time principal as diferenças (Benitez, 2014)

Participar de torneios e campeonatos sub-repticiamente implica a saída em busca de domínios dos lugares pela vista, segundo De Certeau (1998, p. 100), posto que "a divisão do espaço permite uma prática panóptica a partir de um lugar de onde a vista transforma as forças 'estranhas em objetos que se podem observar e medir, controlar, portanto, e 'incluir' na sua visão', transformando as incertezas em espaços legíveis, determinando o poder de conquistar para si um lugar próprio.

\section{Confrontos, Conflitos e Contradições no Futebol de Várzea na CSGBR}

As Táticas de Embate apresentam relatos sobre os confrontos diretos entre os dois times, trazendo à tona as diferenças, contradições e conflitos. Antecipamos que está obvia a existência de rivalidades entre equipes esportivas de quaisquer modalidades, umas defendendo o fair play, outras jogando sujo mesmo. Ainda que por lazer, a prática esportiva traz implícito o desejo de vencer, dado que a vitória simboliza o poder conquistado, ainda que momentaneamente (Bromberger, 1995a; Giulianotti, 2010).

Recortamos nestas discussões esse embate direto justamente porque ambos os times são da comunidade SGBR, ou seja, têm um território comum de convivência, não ignorando, contudo, que puderam existir rivalidades com times de outros bairros. Constata-se que desse confronto direto o Milionários Futebol Clube conquistou mais vitórias sobre o São Gonçalo Beira Rio Futebol Clube. As maneiras de ver as derrotas e vitórias são muito discrepantes. Vejamos:

1. Os dois times era bom... aqui dentro do campo quando um vestia a camisa azul e outro vestia outra camisa sempre tinha rixa que era... aquilo ali, cada um defendia a sua cor... rivalidade dentro do campo, fora não. Fora são todos amigos. É futebol. (Narrador 1) 
2. [...] Aí ficou aquela rixa, mas aquela rixa de futebol, só entre amigos... era a maior rivalidade, era isso aí... era a mesma coisa que jogá Mixto e Operário aqui, naquela época. (Narrador 2)

3. [...] Era uma disputa acirrada mesmo que até hoje... eram muitos irmãos... um jogava no Milionário e outro no São Gonçalo, então virava rivalidade mas era em campo, acabava o jogo todo mundo tava se abraçando...com certeza era uma coisa até curiosa... conflito. (Narrador 4)

4. [...] Pra você vê... dois times daqui e a rivalidade era fortíssimo mais graças a Deus nunca saiu confusão, era mais rivalidade de campo mesmo. (Narrador 6)

5. Tinha rivalidade.. ixi Maria ... até hoje tem. Até hoje tem rivalidade... eles brigava aí.. uma veiz, Ivan mesmo que ta aí é testimunha ... saiu corrido de lá porque a turma num darem na turma (risos).. mas era assim, uma rivalidade danada aqui no São Gonçalo Beira Rio. Sério mesmo, até hoje não é lá essas coisas... rivalidade por causa do futebol porque toda veiz que nóis ia no campo de jogo pra jogá nóis ganhava e nóis ganhava deles direto. Dava goleada neles direto, aqui dentro da...do.. da comunidade, então era uma raiva que tinha, era uma briga, era uma coisa danada mesmo que era sabe? Até hoje ele ainda é... depois que terminava o jogo de futebol era tudo normal, não existia nada, voltava ao normal, mas era uma rivalidade doida, até hoje, até hoje ainda são. Mas eu não dou bola também... era nós mesmo que metia o aço nesse negócio. (Narrador 8 )

6. A rivalidade foi demais porque nosso time era a maioria de jogador da cidade e eles depois que a turma escolheu que correu a notícia que souberam que dispensaram nós, assim como fizeram, aí já ficou a rivalidade que nóis ia com aquela vontade de ganhá deles. E eles nunca ganharam de nóis disputa de campeonato assim, de título de campeão... quando acabô o jogo ... eu fiquei assustado... parece que tinha morrido gente porque gente deles chorava demais na beira do campo... aquela choração assim ... a gente apurado porque não era acostumado com isso, né? (Narrador 9)

Narrativas antagônicas, indicadoras de consumo ou de jogos de forças. Ocupações e dominações de territórios. Modos de falar que refletem as maneiras de fazer de cada um dos times. Em comum, quase todas as narrativas assentem que a rivalidade existia apenas "dentro de campo". Quase todas. Interessam-nos em muito as exceções. De Certeau (1998, p. 104) chama de atividades que correspondem às características das astúcias e das surpresas táticas, "gestos hábeis do "fraco" na ordem estabelecida pelo 
"forte", arte de dar golpes no campo do outro, astúcia de caçadores, mobilidades nas manobras, operações polimórficas, achados alegres, poéticos e bélicos". As rivalidades no futebol representam tipos específicos de paixões coletivas que revelam dramas sociais de cada sociedade (Bromberger, 1995a).

Elias e Scotson (2000, p. 26) explicitam as tensões desse embate da seguinte maneira:

Muitas questões diferentes podem expor às claras as tensões e conflitos entre estabelecidos e outsiders. No fundo, porém, todas são lutas para modificar o equilíbrio do poder; como tal, podem ir desde os cabos-de- guerra silenciosos que se ocultam sob a cooperação rotineira entre os dois grupos, num contexto de desigualdades instituídas, até as lutas francas pela mudança do quadro institucional que encarna esses diferenciais de poder e as desigualdades que lhes são concomitantes. Seja qual for o caso, os grupos outsiders (enquanto permanecem totalmente intimidados) exercem pressões tácitas ou agem abertamente no sentido de reduzir os diferenciais de poder responsáveis por sua situação inferior, ao passo que os grupos estabelecidos fazem a mesma coisa em prol da preservação ou aumento desses diferenciais.

Reportando-nos ao jogo de poder entre os dois times, temos: Havia apenas um time, que expulsou do seu espaço os jogadores mais velhos, mais “inaptos”. Estes, taticamente, organizaram-se em um novo time, convidando estrangeiros à comunidade a defenderem a nova camisa. Resultou disso a reterritorialização ou a busca de novas maneiras de continuar resistindo à opressão dada pela tradição do time mais antigo. Mais ainda, houve uma reversão nos resultados. Diríamos, o tiro saiu pela culatra, ou, o feitiço virou-se contra o feiticeiro. O campo de disputa foi repovoado, tendo-se o futebol de várzea por mediador, ante a presença do Outro (Benitez, 2014).

Sem se resignarem ao dado papel de excluídos, de sem-lugar, aqueles jogadores cujos nomes foram expostos em lista "pregada na parede", astutamente buscaram reforços "fora" do meio comunitário, escalando em campo de batalha jogadores desconhecidos, de outros bairros, e essa tática funcionou de tal maneira que cambiou o discurso: de derrotados, porque excluídos, para vitoriosos nesse embate dentro da comunidade.

Os narradores 1, 2, 4 e 6 pertencem ao time São Gonçalo Beira Rio e em seus relatos podemos observar a admissão de que, de fato, havia uma rivalidade em campo, 
“apenas em campo". Entretanto, os narradores 8 e 9, ademais de admitir essa rivalidade em campo, enfatizam que ela existiu fora de campo também, e que existe ainda nos dias atuais. As rivalidades no futebol são o combustível para sua sobrevivência e expansão, pois motiva os adeptos a seguirem assistindo e praticando o futebol (Giulianotti, 2010).

"Enquanto um limite firme é mantido entre os territórios e a ferida narcísica está contida, a agressividade será projetada no Outro ou no Exterior", explicita De Certeau (1998, p. 211) sobre o caráter liminar do "signo" do social que desliza incessantemente de uma posição à outra. Temos, então, uma flutuação e uma bifurcação. Prorrogação do tempo liminar de jogo e ampliação do campo de embates. O imanente e o deslizante, movimentos diferentes sobre um território comum.

De um lado, os termos de referência do discurso local dominante, de manutenção da tradição e, como força antagônica, desponta - saindo da reserva - poderes guardados que generalizam esse discurso, que escalam como titulares os discursos heterogêneos, criadores de espaços híbridos receptivos ao Outro.

Diz ainda o autor serem produções de "efeitos de identidade" no jogo de um poder que é elusivo porque não esconde nenhuma essência. Criam ambivalências em que tais efeitos de identidade são divididos, destacam a cisão que bifurca os discursos sobre a realidade daquelas rivalidades. Enquanto uns narradores ignoram a persistência no lugar, na comunidade, daquela antiga rivalidade, recusando-a e substituindo-a pela repetição, pela rearticulação da "realidade" como mímica; outros narradores, opostamente, levam em consideração essa realidade latente, existente, esse 'caso' mal resolvido que ainda causa mal-estar e, supomos, ainda divide aquele território e seu povo.

Naquela pequena comunidade SGBR, como em outras - supomos -, começaram a surgir pequenos efeitos ou reflexos do grande campo de batalha que vai desde a cultura dita superior até a cultura no sentido puramente antropológico, de maneiras de fazer, de usos e costumes. Daí resulta evidente o deslocamento discursivo daquela comunidade que viu como oportuno o momento da crise cultural local como saída tangencial do problema a ser enfrentado (Benitez, 2014).

Reterritorialização. Uniu-se, no espaço da criação de um novo time, na "oportunidade" advinda do deslocamento de alguns jogadores, uniram-se útil e agradável. Invenções do cotidiano, diria De Certeau. Estamos falando de política, de desejo de conquista de poder. De relações de poder, seguramente. Outro espaço surge, então. Mas, hoje, que espaço é esse? 


\section{CONSIDERAÇÕES FINAIS}

Neste Século XXI, a força da cultura local, do cotidiano que evidencia o jogo social nas lutas pelo poder (jogo este em que identidades e diferenças se imbricam de maneira provocativa na arte de atuar no mundo), possibilita registrar estas palavras com a força de (re)começo do papel de mediador que o futebol de várzea consolidou naquela comunidade.

Ao pesquisar e conduzir nossas percepções através da indagação inicial: Que papel teria o futebol de várzea na mediação das diferenças locais, que maneiras de fazer sua prática interatuam e modificam o espaço e as relações?, adentramos em territórios desconhecidos e prazenteiros, repletos de pessoas e confrontos sociais mediados no espaço delimitado pelo campo de futebol de várzea.

Implícitos ou explícitos se revelam estranhamentos e aproximações, que decorrem da manutenção de campos de atuação, às vezes desterritorializando o estrangeiro ou forasteiro que aí tenta se situar, às vezes provocando reacomodações ou reterritorializações, tanto entre os estabelecidos naquela comunidade quanto entre os outsiders ou estranhos ao meio. Para tanto, a partida em busca dos percursos ou trajetórias das maneiras de fazer dos times São Gonçalo Beira Rio e Milionários Futebol Clube cobrou-nos esmiuçar, através da entrevista oral, relatos da história de vida desses dois grandes times de futebol de várzea.

Percebemos, assim, oportuna a apropriação dos termos "tática" e "estratégia" difundidos pelas teorias certeaunianas. Dessa maneira, partimos do começo, da fundação dos dois times, dos conflitos ali evidenciados para que pudéssemos chegar às maneiras de se relacionarem essas duas equipes, no campo de futebol de várzea.

Constatamos, então, que cada qual manteve uma tática organizacional diferenciada, com transgressões (como o caso da introdução de uma dirigente mulher na equipe do Milionários) e, ainda, que através do futebol de várzea esses conflitos foram exacerbados durante os embates em jogo, com participação da comunidade nas torcidas organizadas.

Aprofundamos mais ainda, ao deparar-nos com intensa participação da comunidade ao redor do campo de futebol de várzea, observando, por exemplo, que a vida na e da comunidade São Gonçalo Beira Rio, como pudemos constatar, ganhava outro ritmo nos dias de jogos, e o cotidiano da rotina caseira quebrava-se e transformava-se em outras rotinas que o campo de futebol exigia dos moradores.

Mas, sobretudo, os relatos que começaram com a fundação dos times, foram se 
aproximando do momento atual, de maneira que cada entrevistado pôde - pelo menos por alguns minutos - parar e refletir sobre aquele tempo, aquelas disputas e as relações daí advindas. Muitos sentimentos se enviesaram nessas reflexões, à exceção da indiferença.

Entre todos os que colaboraram nas entrevistas, podem-se perceber saudades, alegrias, decepções, rivalidade, coragem, companheirismo, menos a indiferença. Há um sentimento de afeto pelo futebol de várzea naquela comunidade, cada qual amando à sua maneira a história de seu time, fato evidenciado quando alguns revelaram o desejo de sua retomada, dos campeonatos, de dar nova vida aos campos ali existentes.

Novas maneiras de fazer aquele cotidiano. Novas, porque em outro território foi (trans)formado, como consequência daqueles embates sociais. Percorrendo o mapa, pequeno tanto quanto a extensão da comunidade São Gonçalo Beira Rio, evidenciamos que a conectividade ultrapassa as demarcações geossociais, cujo laço de manutenção reside nas diferenças, que são múltiplas, desde as maneiras cotidianas de fazer o futebol de várzea às aceitações de grupos sociais distintos.

Temos então que inexiste uma unicidade, mas que a multiplicidade constitui aquelas relações mediadas pelo futebol de várzea. Dentro dos próprios times, pudemos perceber claramente as diferenças discursivas: uns mais conservadores ou resistentes, outros mais receptivos ao desconhecido, ao novo.

Mas o fio condutor de todos os conflitos, provocador da ruptura a-significante, reside naquele ato de expor publicamente o nome de jogadores excluídos, evidente conflito territorializado na comunidade estudada. Se ali existiu alguma hierarquização, ela se evidenciou na questão "habilidade", porque todos os atores dos dois times - em geral e com poucas exceções - advêm de um quadro socioeconômico que os situa em mesmo nível, mantendo, assim, o mesmo capital simbólico.

Nesse sentido, voltando um pouco à história da comunidade, vemos que as táticas de jogo social foram passando - de período a período - por atividades variadas. Como exemplo, houve um período de evidência para a atividade da pesca, depois foi o futebol de várzea que alcançou o auge, inserindo-se na história mato-grossense desse esporte, e logo em seguida foram as manifestações culturais exacerbadas pelos artesanatos, cerâmicas e dança folclórica que movimentaram (e ainda o fazem) a comunidade SGBR. Como consequência, têm estimulado o surgimento e a manutenção de restaurantes com base na pesca e a venda dos produtos culturais ali produzidos. 


\section{REFERÊNCIAS}

Azevedo, D. F. (2006). Da precariedade do futebol de várzea e do teatro ao imaginário popular como forma de resistência cultural. Universidade Federal Fluminense. Artigo acadêmico. Disponível em http://www.eba.ufrj.br/ppgav/lib/exe/fetch. php?media=anais_encontros:xiii:18.pdf. Acesso em 18/03/2013.

Benitez, A. (2014). O futebol de Várzea como mediador cultural na Comunidade São Gonçalo Beira Rio em Cuiabá/MT. Dissertação (Mestrado em Estudos de Cultura Contemporânea). PPGECOO - Universidade Federal de Mato Grosso.

Bromberger, C. (1995a). Le match de football: ethnologie d'une passion partisane à Marseille, Naples et Turin. Paris: Éditions de la Maison des Sciences de l'Homme.

Bromberger, C. (1995b). De quoi parlent les sports? Terrain. Des Sports, n. 25, septembre, 5-12.

Bromberger, C. (2008). As práticas e os espetáculos esportivos na perspectiva da etnologia. Horizontes Antropológicos, v. 14, n. 30, 237-253.

Caballé, A. (1995). Narcisos de tinta: Ensayo sobre la literatura autobiográfica em lengua castellana (siglo XIX y XX). Madrid: Megazul.

Cipriani, R., Pozzi, E., \& Corradi, C. (1985). Histoires de vie familiale dans un contexte urbain. Cahiers Internationaux de Sociologie, v. 79, 253-262.

De Certeau, M. (1998). A invenção do cotidiano: artes de fazer. 3. ed. Petrópolis/RJ: Vozes.

Deleuze, G., \& Guattari, F. (1998). Mil platôs: capitalismo e esquizofrenia. Tradução de Suely Rolnik. v.4. São Paulo: Ed. 34. 176 p.

Dumazedier, J. (1975). Lazer e Cultura Popular. São Paulo: Editora Perspectiva. (Coleção Debates).

Elias, N., \& Scotson, J. L. (2000). Os estabelecidos e os outsiders: sociologia das relações de poder a partir de uma pequena comunidade. Trad. Vera Ribeiro. Rio de Janeiro: Jorge Zahar Editor. 224p. Disponível em http://books.google.com.br/books/ about/Os_Estabelecidos_e_os_Outsiders.html?idt=cq2qM9xUS68C\&redir_ esc $=\mathrm{y}$. Acesso em 26/12/2013. 
Giulianotti, R. (2010). Sociologia do futebol: dimensões históricas e socioculturais do esporte das multidões. São Paulo: Nova Alexandria.

Koogan, A., \& Houaiss, A. (1993). Enciclopédia e dicionário ilustrado (p. 815). Rio de Janeiro: Delta.

Lakatos, E. M., \& Marconi, M. A.. (2000). Metodologia científica. 3.ed. São Paulo: Atlas.

Mostafá, S. P., \& Nova Cruz, D. (2009). Para ler a filosofia de Gilles Deleuze e Félix Guattari. Campinas, SP: Editora Alínea.

Moura, M. L. S., \& Ferreira, M. C. (2005). Projetos de pesquisa: elaboração, redação e apresentação. Rio de Janeiro: EDUERJ. 